\title{
MiR-128 up-regulation inhibits Reelin and DCX expression and reduces neuroblastoma cell motility and invasiveness
}

\author{
Cristina Evangelisti, ${ }^{, 1}$ Maria Carolina Florian, ${ }^{\dagger, 1}$ Isabella Massimi, ${ }^{\ddagger}$ Carlo Dominici, $,{ }^{,}, \|, \mathbb{I}$ \\ Giuseppe Giannini, ${ }^{\ddagger}$ Silvia Galardi,* Maria Cristina Buè,* Simone Massalini,* \\ Heather P. McDowell, ${ }^{\S, \#}$ Elio Messi, ${ }^{\dagger}$ Alberto Gulino, ${ }^{\ddagger}{ }^{\ddagger *} *$ Maria Giulia Farace, ${ }^{*}$ and \\ Silvia Anna Ciafrè ${ }^{*, 2}$ \\ *Department of Experimental Medicine and Biochemical Sciences, University of Rome "Tor \\ Vergata," Rome, Italy; ${ }^{\dagger}$ Dipartimento di Endocrinologia, Fisiopatologia e Biologia Applicata, Facoltà \\ di Farmacia, Università degli Studi di Milano, Milan, Italy; ${ }^{\ddagger}$ Department of Experimental Medicine \\ and ${ }^{\$}$ Department of Pediatrics, University of Rome "La Sapienza," Rome, Italy; "Laboratory of \\ Oncology, Bambino Gesù Children's Hospital, Rome, Italy; "Division of Child Health, School of \\ Reproductive and Developmental Medicine, Liverpool University, Liverpool, UK; ${ }^{\#}$ Division of \\ Oncology, Royal Liverpool Children's National Health Service Trust Alder Hey, Liverpool, UK; and \\ **Neuromed Institute, Pozzilli, Italy
}

ABSTRACT MicroRNAs are a class of sophisticated regulators of gene expression, acting as post-transcriptional inhibitors that recognize their target mRNAs through base pairing with short regions along the $3^{\prime}$ UTRs. Several microRNAs are tissue specific, suggesting a specialized role in tissue differentiation or maintenance, and quite a few are critically involved in tumorigenesis. We studied miR-128, a brain-enriched microRNA, in retinoic acid-differentiated neuroblastoma cells, and we found that this microRNA is up-regulated in treated cells, where it down-modulates the expression of two proteins involved in the migratory potential of neural cells: Reelin and DCX. Consistently, miR-128 ectopic overexpression suppressed Reelin and DCX, whereas the LNA antisensemediated miR-128 knockdown caused the two proteins to increase. Ectopic miR-128 overexpression reduced neuroblastoma cell motility and invasiveness, and impaired cell growth. Finally, the analysis of a small series of primary human neuroblastomas showed an association between high levels of miR-128 expression and favorable features, such as favorable Shimada category or very young age at diagnosis. Thus, we provide evidence for a role for miR-128 in the molecular events modulating neuroblastoma progression and aggressiveness.-Evangelisti, C., Florian, M. C., Massimi, I., Dominici, C., Giannini, G., Galardi, S., Buè, M. C., Massalini, S., McDowell, H. P., Messi, E., Gulino, A., Farace, M. G., Ciafrè, S. A. MiR-128 up-regulation inhibits Reelin and DCX expression and reduces neuroblastoma cell motility and invasiveness. FASEB J. 23, 4276-4287 (2009). www.fasebj.org

Key Words: MicroRNA $\cdot$ tumor $\cdot$ neuronal $\cdot$ retinoic acid

MicrornAS ARE SMALL ( $\sim 22 \mathrm{nt})$, noncoding RNAs that act as negative regulators of gene expression at a post-transcriptional level (1). Their regulatory activity is performed via either the degradation of their specific target mRNAs or the inhibition of mRNA translation $(2,3)$. In most cases, animal microRNAs bind to their target mRNAs through the recognition of complementary sequences located in the $3^{\prime}$ UTRs of mRNAs. The minimal requirement allowing functional binding of a microRNA to its target mRNA is usually represented by a short sequence in the $3^{\prime} \mathrm{UTR}$ that is perfectly complementary to nucleotides $2-8$ at the $5^{\prime}$ of the microRNA itself. The interaction between this region of the microRNA (called the "seed" region) and its complementary ones along a mRNA $3^{\prime}$ UTR is one of the key parameters taken into account by the commonly accepted prediction algorithms employed to identify which mRNAs can be regulated by one microRNA (4). Because of the very short region of complementarity that governs the functional interaction between a microRNA and its targets, it is easy to understand how one single microRNA can hit many different target mRNAs and can perform its regulatory action in different ways by "choosing" distinct targets, depending on the specific cell environment where it is functioning (5, $6)$. The expression of some microRNAs can be ubiquitous, but for others, a high specificity is well documented. MicroRNAs, which are enriched or even selectively expressed only in the central nervous system (CNS), represent undoubtedly the largest class of tissue-specific microRNAs: a surprisingly higher num-

\footnotetext{
${ }^{1}$ These authors contributed equally to this work.

2 Correspondence: Department of Experimental Medicine and Biochemical Sciences, University of Rome "Tor Vergata," Via Montpellier, 1, 00133 Roma, Italy. E-mail: ciafre@uniroma2.it

doi: 10.1096/fj.09-134965
} 
ber of unique microRNAs have been isolated from neuronal tissues or cell lines than from any other cell type (7). Among these, miR-128 is a brain-enriched microRNA, which is transcribed from two gene copies located on chromosomes 2 and 3. These two genes, named miR-128-1 and miR-128-2, respectively, produce two microRNAs that are identical in their mature forms.

Although first microRNAs were discovered relatively recently $(8,9)$, much research has been performed demonstrating their key role in normal development and cancer. Our group has previously shown that miR-128 is significantly down-regulated in glioblastoma multiforme (GBM), a highly malignant CNS tumor (10).

Neuroblastoma is the most frequently occurring solid tumor in childhood and derives from precursor cells of the ganglionic lineage of the sympathetic nervous system (SNS) $(11,12)$. It is a highly lethal malignancy, accounting for around $15 \%$ of all pediatric oncology deaths. Approximately half of the cases are classified as high risk, with overall survival rates of $\sim 40 \%$ despite intensive multimodal treatment (13), and are characterized by a propensity to metastasize, especially to bone, bone marrow, and distant lymph nodes (11). Despite many advances in understanding the molecular basis of this neoplasm, the molecular pathways leading to neuroblastoma development remain obscure, and a better elucidation of the molecular features of this tumor is mandatory.

DCX, the protein product of the gene doublecortin, located on chromosome $\mathrm{X}$, is a microtubule-associated protein required for neuroblastic migration during cerebral cortex development (14). DCX expression in migrating neurons spans from embryonic to postnatal development, while in adult rodents and humans, only a few cells express this protein, notably those located in brain regions where neurogenesis is retained, such as the hippocampus or the subventricular zone of the lateral ventricular walls (15-18). DCX expression is also detectable in some tumors of the nervous system, such as GBM and neuroblastoma. In GBM, DCX expression is associated with a poor outcome and has been proposed as a marker of a migratory state of tumor cells (19-21). In neuroblastoma, DCX expression has been demonstrated in primary tumors and metastatic sites disease (22); moreover, in neuroblastoma cell lines, this protein appears to be expressed exclusively in highly mobile and invasive cells (23).

Another protein that affects neuronal migration during development, even if through a totally different mechanism, is Reelin, a high-molecular-weight secreted glycoprotein, which is thought to play its role as a guide for migratory neurons via the interaction with two cell surface receptors, the very low density lipoprotein receptor (VLDLR) and the apolipoprotein E receptor 2 (ApoER2), then triggering a tyrosine kinase signaling cascade (24). However, the expression of this protein is not restricted to the CNS, as it has been found in some adult peripheral tissues and tumors. For example,
Reelin has been shown to be a positive marker for prostate carcinoma aggressiveness (25) and is overexpressed in retinoblastoma (26) and esophageal carcinoma (27).

In the present study, we sought to investigate whether miR-128 expression is modulated in neuroblastoma, and whether its expression can be associated with different features contributing to the aggressiveness of this tumor, possibly through modulation of genes affecting neuroblastoma cell motility, such as DCX and Reelin. To this aim, we measured miR-128 expression after in vitro ATRA treatment of SH-SY5Y neuroblastoma cells, and we also evaluated the expression of the two predicted targets Reelin and DCX, in search of a possible inverse correlation with miR-128 expression. MiR-128 ectopic overexpression and knockdown studies were also performed, in order to unequivocally assign the observed DCX and Reelin protein variations solely to miR-128 expression and to correlate them with the general inhibitory effect exerted by miR-128 on SH-SY5Y neuroblastoma cell growth, migration, and invasive potential. Finally, we measured the expression levels of miR-128 in neuroblastoma samples obtained at diagnosis from patients with locoregional vs. metastatic disease, in search of a possible clinical significance of miR-128 dosage in neuroblastoma.

\section{MATERIALS AND METHODS}

\section{Cell lines and transfections}

SH-SY5Y and HEK293 were maintained in DMEM supplemented with $10 \%$ heat-inactivated fetal bovine serum, $20 \mathrm{mM}$ L-glutamine, $100 \mathrm{U} / \mathrm{ml}$ of penicillin $\mathrm{G}$ sodium, and 100 $\mu \mathrm{g} / \mathrm{ml}$ streptomycin sulfate in a humidified atmosphere containing $5 \% \mathrm{CO}_{2}$ at $37^{\circ} \mathrm{C}$. Transfections were performed by Lipofectamine 2000 reagent (Invitrogen, Carlsbad, CA, USA) in Opti-MEM I (Invitrogen), as recommended by the manufacturer, and stable transfectants were selected by adding 0.6 $\mathrm{mg} / \mathrm{ml}$ G418 to the culture medium.

\section{Treatment with retinoic acid $(\mathbf{R A})$}

All-trans RA (ATRA; Sigma, St. Louis, MO, USA) was added to a final concentration of $10 \mu \mathrm{M}$. SH-SY5Y cells were plated at a density of $1 \times 10^{6}$ cells/10-cm-diameter Petri dish and grown in MEM supplemented as described above. For each experiment, ATRA was diluted at the desired concentration directly into the growth medium. The $10 \mu \mathrm{M}$ ATRA treatment started on the second day after plating, concomitantly with the medium replacement. Cells were fed every $48 \mathrm{~h}$ with control, or ATRA-containing fresh medium, and the treatment was stopped $6 \mathrm{~d}$ after the first addition of ATRA.

\section{Neurite outgrowth assay}

For each treatment, phase-contrast microscopic images were acquired from 3 wells, and the total numbers of cells and the numbers of neurites were counted in 5 randomly chosen fields. A neurite was defined as a process $\geq 1$ cell body (average diameter of cell bodies of control cells at d 0 ) in length extending from the cell (28). Acquired images were 
analyzed by Image J software (National Institutes of Health, Bethesda, MD, USA), and the mean \pm SD values of neurite length were determined for each treatment.

\section{MiR-128 knockdown}

The antisense LNA oligonucleotide against miR-128, and a negative control oligonucleotide, were obtained from Ambion (Austin, TX, USA). Knockdown oligos were transfected by siPORT NeoFX (Ambion) into SH-SY5Y cells $\left(1.4 \times 10^{6}\right.$ cells / 10-cm-diameter Petri dish) at a final concentration of 40 nM. A FAM-labeled negative control LNA oligonucleotide (AM 17012; Ambion) was transfected in the same conditions as those used for the unlabeled LNA molecule and used for measuring transfection efficiency by fluorescence microscopy at $24 \mathrm{~h}$ after transfection. Transfection efficiency was estimated as $\sim 90 \%$. The day following transfection, medium was changed to all samples, and replaced with $10 \mu \mathrm{M}$ ATRAcontaining medium or mock medium. From this time point on, the ATRA treatment was performed as described above, and it was stopped $6 \mathrm{~d}$ after the first addition of ATRA, when the cells were lysed for total protein and RNA extraction (for details, see below).

\section{Plasmid constructs}

The miR-128 sequence was amplified by PCR from genomic human DNA using the following primers: sense, 5'-GAA-

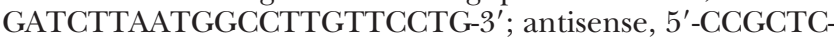
GAGGTGGAAACCTGAGTAAAA-3'. The correct sequences of amplified products were verified by sequencing and cloned between the $K p n I$ and XhoI sites of pCDNA $(+) 3.1$ vector (Invitrogen), deprived of its polyadenylation sequence, to obtain DpA-miR-128. We chose to excise the polyadenylation signal from the original vector, as we had previously observed that its presence impaired miR-128 expression (data not shown).

We used pRL-TK plasmid (coding for Renilla luciferase; Promega, Madison, WI, USA) to construct the miR-128 target site reporters, and the pGL3 plasmid (coding for Firefly luciferase; Promega) as a control to normalize the transfection efficiency. DNA oligonucleotides containing both target sequences for miR128 identified in the 3'UTR of Reelin and DCX mRNAs were purchased as single-strand molecules. Their sequences were reelin wild-type sense, 5'-CTAGTACTTTCCCACACTGTGAACTAAGACAATAAGAGTTTTTTCATTGTGTTTTCTTCTCTAGAGC-3'; reelin wild type antisense, 5'-GGCGGCTCTAGAGAAGAAAACACAATGAAAAAACTCTTATTGTCTTAGTTCACAGTGTGGGAAAGTA-3'; reelin mutated sense, 5'-CTAGTCATTTCCCAAGTGTCACACTAAGACAATAAGAGTTTTTTTGTGTCACTTTCTTCTCTAGAGC-3'; reelin mutated antisense, 5'-GGCCGCTCTAGAGAAGAAAGTGACACAAAAAAACTCTTATTGTCTTAGTGTGACACTTGGGAAATGA-3'. DCX wild type sense, 5'-CTAGTCTGAAAACACTGTGAGAATTTGGACAATAAGAGCTGTGAACTGTGAGTGCTGAATCTAGAGC-3'; DCX wild type antisense, 5'-GGCCGCTCTAGATTCAGCACTCACAGTTCACAGCTCTTATTGTCCAAATTCTCACAGTGTTTTCAGA-3'; DCX mutated sense, 5'-CTAGTCTGAAAAAGTGTCACGAATTTGGACAATAAGAGCTGTGAGTCACTAGTGCTGAATCTAGAGC-3'; DCX mutated antisense, 5'-GGCCGCTCTAGAT T CA GCACTAGT GACTCACAGCTCT TAT T GTCCAAATTCGTGACACTTTTTCAGA-3' . Oligonucleotides were annealed and the double-strand products were inserted into $\mathrm{pRL}-\mathrm{TK}$ vector in a tandem duplicate (resulting in 2 copies of each of the 2 predicted sites) between the XbaI and NotI sites, immediately downstream of the Renilla luciferase stop codon. All plasmid constructs were verified by sequencing.

\section{Cell viability assay}

Cell viability was measured by using Promega's Cell Titer Aqueous assay with MTS tetrazolium, in which viable cells convert MTS tetrazolium into a formazan-colored product $\left(\mathrm{OD}_{490 \mathrm{~nm}}\right)$. Cells $(3000 /$ well $)$ were seeded in a 96-well plate. The cell growth was then measured 48 and $96 \mathrm{~h}$ after cell adhesion, following the manufacturer's instructions.

\section{RNA extraction and Northern blot analysis}

Total RNA was extracted from SH-SY5Y cells with TRIzol reagent (Invitrogen), according to the manufacturer's instructions. For Northern blot analysis of miRNAs, $20 \mu \mathrm{g}$ of total RNA were separated on $10 \%$ denaturing polyacrylamide gels and electrotransferred to Immobilon Nylon ${ }^{+}$membrane (Millipore Corp., Bedford, MA, USA). The specific probes, end-labeled by $\mathrm{T} 4$ polynucleotide kinase in the presence of $\left(\gamma^{-32} \mathrm{P}\right)$ ATP, were miR-128, 5'-AAAAGAGACCGGTTCACTGTGA-3' ${ }^{\prime}$; and U6, 5' -CACGAATTTGCGTGTCATCCTTGCGCAGGGGCC-3'. Bands were quantified with ImageJ $1.34 \mathrm{~s}$ or OptiQuant 3.1 software (Packard Instruments, Meriden, CT, USA).

\section{Reverse transcription and real-time PCR}

For Reelin and DCX mRNA detection, $1 \mu \mathrm{g}$ of total RNA, previously treated with DNase (Sigma), was retrotranscribed using the High Capacity cDNA Archive Kit (Applied Biosystems, Applera Italia, Monza, Italy).

Real-time PCR was performed using $1 \mu \mathrm{l}$ of cDNA and iTaq SYBR Green Supermix with ROX (Bio-Rad, Hercules, CA, USA) in an ABI Prism 7000 Sequence Detection System (Applied Biosystems), and amplifications were performed in triplicate and repeated twice. Changes in DCX and reelin mRNA amounts were quantified by using the $\Delta \Delta \mathrm{C}_{\mathrm{t}}$ method for relative quantitation of gene expression $(29,30)$.

Primer sequences were as follows: GAPDH-1-F 5'GAAGGTGAAGGTCGGAGTC-3'; GAPDH-2-R 5'-TTGATGGCAACAATATCCACTT-3'; DCXH-8-F 5'-CCTCAGGGAGTGCGTTACAT-3'; DCXH-9-R 5'-ATAGCTTTCCCCTTCCTCCA-3'; REL-1-F 5'-CATTGGAGGTTCCAGTGCTT-3'; REL-2-R 5'-TCACGTGAGAGGCTACCACA- 3 '.

For the detection of mature miR-128, reverse-transcriptase reactions contained $50 \mathrm{ng}$ of total RNA that was reverse transcribed using the High Capacity cDNA Archive Kit (Applied Biosystems).

Real-Time PCR was performed using a miRNA-specific Taq-Man Assay (Applied Biosystems) in an Applied Biosystems 7900HT Sequence Detection System. U6 snRNA was used for normalization.

\section{Protein gel electrophoresis and immunoblotting}

Cells were lysed with modified RIPA buffer $(50 \mathrm{mM}$ Tris-HCl, pH 7.4; $150 \mathrm{mM} \mathrm{NaCl} ; 0.1 \%$ Tryton X-100; $0.25 \%$ Nadeoxycholate; $0.1 \mathrm{M} \mathrm{EDTA}$; and 1\% SDS) containing protease (ABESF, leupeptin, and pepstatin) and phosphatase inhibitors $\left(1 \mathrm{mM} \mathrm{NaF}\right.$ and $\left.1 \mathrm{mM} \mathrm{Na} \mathrm{VO}_{4}\right)$. Proteins $(50-70 \mu \mathrm{g})$ were separated on SDS-12\% (10\% for Gap43) PAGE under reducing conditions and transferred onto nitrocellulose membranes. Primary antibodies used were the following: antiDCX (C-18 sc-8066; 1:500) and anti-LIS1 (H-300 sc-15319; 1:200) from Santa Cruz Biotechnologies (Santa Cruz, CA, USA); antivimentin (1:10,000), anti-Gap43 (clone GAP-7B10, 1:4000), antiactin (1:1000), and anti- $\alpha$-tubulin (1:500) from Sigma. The secondary antibodies used were HRP-conjugated anti-goat (for anti-DCX antibody), anti-rabbit (for anti-LIS1), and anti-mouse (for anti- $\alpha$ tubulin, anti-- $\beta$-actin, anti-Gap43, and anti-vimentin antibody) from 
Santa Cruz Biotechnologies. Detection and visualization of proteinbound antibodies was achieved using an enhanced chemiluminescence WB detection kit (ECL Plus; Amersham Biosciences, Piscataway, NJ, USA). To quantify the intensity of the bands, membranes were scanned and analyzed with the Image J software.

For the miR-128 knockdown experiment, we wanted to visualize both DCX and Reelin in the same intracellular protein extracts, in order to be able to compare directly these two proteins and the endogenous control protein, $\beta$-tubulin. To this aim, $70 \mu \mathrm{g}$ of proteins was separated onto a $3-8 \%$ NuPAGE Novex precast gradient gel (Invitrogen) and transferred onto nitrocellulose membranes. Primary and secondary antibodies for DCX and $\beta$-tubulin detection were the same as described above, and for Reelin detection mAb 142 (MAB5366; Chemicon, Temecula, CA, USA) was employed as the primary antibody, with a secondary horseradish peroxidase-conjugated antibody (AP160P; Chemicon).

For analyzing Reelin secretion into supernatants, cells were plated onto $60-\mathrm{mm}$ dishes and grown for $24 \mathrm{~h}$; then cells were washed twice with PBS, and serum-free medium was added and kept for the following $24 \mathrm{~h}$, after which the supernatants were collected, cleared by a brief centrifugation at $4^{\circ} \mathrm{C}$, concentrated $\sim 30$ times by Centricon Plus-20 (Millipore), and stored at $-80^{\circ} \mathrm{C}$. Concentrated supernatants were separated on $6 \%$ SDS-PAGE gels and transferred to nitrocellulose membrane. Western blot was performed by using mAb 142 (MAB5366; Chemicon). The secondary horseradish peroxidase-conjugated antibody (AP160P; Chemicon) was detected using ECL Plus Western blotting detection reagents (Amersham Biosciences). Bands were quantified with ImageJ 1.34 or OptiQuant 3.1. Ponceau staining of the blots was used to normalize immunoreactive Reelin signal, as no secreted endogenous control of a comparable molecular weight is available, to our knowledge, for normalization.

\section{Assay of luciferase activity}

HEK293 cells were seeded in 24-well plates $24 \mathrm{~h}$ before transfection. Cells were cotransfected with $1 \mu \mathrm{g}$ of DpA-miR128 (miR-128) or empty vector $(D p A), 50 \mathrm{ng}$ of target reporter (wild-type or mutated), and $5 \mathrm{ng}$ of pGL3 control in the presence of Lipofectamine2000 reagent (Invitrogen). Fortyeight hours after transfection, the luciferase activity was determined using the dual-luciferase assay system (Promega), according to the manufacturer's instructions. The Renilla luciferase activity was normalized by dividing by the Firefly luciferase activity of the same transfection, and the normalized luciferase activity in empty vector transfection was set to 1.0 as a reference.

\section{DCX immunofluorescence analysis}

Cells were grown on 13-mm-diameter coverslips, fixed in $4 \%$ paraformaldehyde (PFA), and permeabilized in $0.2 \%$ Triton $\mathrm{X}-100$, and the unspecific sites were blocked in $10 \%$ normal donkey serum (Sigma) in PBS. Subsequently, cells were incubated with the primary antibody (anti-DCX, C-18 sc-8066; 1:500; Santa Cruz Biotechnology) for $1 \mathrm{~h}$ at room temperature and then rinsed with PBS. As a secondary antibody, Cy3-conjugated anti-goat (Jackson ImmunoResearch, West Grove, PA, USA) was used ( $1 \mathrm{~h}$ at room temperature). Nuclei were stained with DAPI (Sigma-Aldrich). Finally, the cells were washed in PBS before mounting using Mowiol 40-88 (Sigma-Aldrich).

\section{Wound-scratch assay}

To investigate cell migration capability, a modified woundscratch assay was used $(31,32)$. Briefly, cells were grown to confluent monolayers, and when approaching $100 \%$ cell confluence, the monolayers were wounded by scratching the surface as uniformly as possible with a pipette tip. This initial wounding and the movement of the cells in the scratched area was photographically monitored using the Axiovert Zeiss 200 microscope (Carl Zeiss, Oberkochen, Germany) with an $\times 10$ (NA 0.25) objective linked to a Coolsnap Es chargecoupled device camera (Roper Scientific-Crisel Instruments, Rome, Italy) for $24 \mathrm{~h}$. The migration rate is expressed as a percentage of the control, and it was calculated as the proportion of the mean distance between both borderlines caused by scratching, to the distance that remained cell-free after regrowing (31). Two independent series of experiments were performed in quadruplicate.

\section{Cell invasion assay}

Cell invasion was determined by a modified microchemotaxis assay (33) using cell culture 24-well inserts with the bottom sealed by an 8 - $\mu \mathrm{m}$-pore polycarbonate filter coated with Matrigel (Chemicon). Briefly, $2.5 \times 10^{5}$ cells in $250 \mu \mathrm{l}$ of serum-free MEM were seeded into the inserts. Chambers were incubated at $37^{\circ} \mathrm{C}$ in a $5 \% \mathrm{CO}_{2}$ atmosphere for $48 \mathrm{~h}$. The cells migrated to the underside of the coated filter were incubated with cell-detachment buffer and dissociated from the filter. The cells were then lysed and stained by CyQuant GR dye. Fluorescence was counted using Victor ${ }^{3}$ multilabel readers (PerkinElmer, Wellesley, MA, USA). Data are expressed as means $\pm \mathrm{SE} ; n=4$.

\section{Image acquisition}

Images were acquired using the UIC-Metavue 6.2.2 (UICCrisel Instruments) imaging system on an Axiovert Zeiss 200 microscope. An oil immersion $63 \times(\mathrm{NA} \mathrm{1.4)}$ or a $40 \times(\mathrm{NA}$ $0.8)$ objective was used for IF images.

For the wound scratch test analysis, images were acquired using a $10 \times($ NA 0.25$)$ objective. The distance between the borderlines of the scratched area was measured using the Region Measurement Function included in UIC-Metavue 6.2.2.

\section{Tissue collection}

Tumor samples from primary site were obtained by surgery from 28 children with newly diagnosed neuroblastoma admitted to the Department of Pediatrics at Sapienza University and to the Division of Oncology at Royal Liverpool Children's National Health Service Trust Alder Hey. No selection criteria were applied except for the availability of adequate tumor tissue for the analysis. Institutional written informed consent was obtained from the patient's parents or legal guardians. The study underwent ethical review and approval according to local institutional guidelines. Patients, 16 males and 12 females, were aged from $1 \mathrm{~d}$ to 336 mo (median, $25 \mathrm{mo}$ ). Primary site was adrenal in 17 patients, abdominal nonadrenal in 9, and thoracic in 2. Histopathological grading was carried out according to the International Neuroblastoma Pathology Classification (34), and the final clinical-pathological diagnosis fulfilled the International Criteria for Neuroblastoma Diagnosis (35). The 28 patients were staged according to the International Neuroblastoma Staging System (35): 9 patients were at stage 1, 2 at stage 2,1 at stage 3,15 at stage 4 , and 1 at stage $4 \mathrm{~S}$. As of December 2008, the median follow-up for the 28 patients was 53 mo (range: 1 to 147). In 16 disease-free (DF) patients, a median follow-up of $95 \mathrm{mo}$ (range 48 to 147 ) was observed. In the remaining 12 patients, either dead of complications (DOC, $n=1$ ) or dead of disease (DOD, $n=11$ ), a median follow-up of 9 mo (range 1 to 44 ) 
was recorded. All clinicopathological features of the patients are included in Supplemental Table 1.

\section{Statistical analysis}

Results of quantitative analysis of in vitro experiments are presented as means $\pm \mathrm{SE}$ or $\mathrm{SD}$, as specified in the figure legends. Control and treated samples were compared by the 1-sided unpaired Student's $t$ test or by ANOVA and using the GraphPad Prism 4.0 software (GraphPad, San Diego, CA, USA). The results were considered statistically significant $v s$. the untreated cells, with a probability level of $P<0.05$, or highly statistically significant with a probability level of $P<0.001$.

For patient samples, associations between miR-128 expression and clinicopathological features were evaluated using the 2-sided Student's $t$ test for independent samples, with a significance level of 0.01 . Original data were previously log transformed to stabilize the variance. To investigate on survival, the 28 patients were divided into two groups with "low" and "high" expression using the miR-128 median value of 0.749 as cutoff point, and survival curves were computed for each group using the Kaplan-Meier method. The difference between curves was assessed by log-rank test, using SPSS for Windows (SPSS Inc., Chicago, IL, USA).

\section{RESULTS}

\section{MiR-128 expression is up-regulated following ATRA treatment of neuroblastoma cells}

On the basis of both in vitro and in vivo data, it is widely recognized that the degree of differentiation of neuroblastoma cells is a good predictor of patient outcome. The availability of chemical agents that are able to induce the in vitro differentiation of human neuroblastoma cell lines has highlighted neuroblastoma cell lines as a very interesting model of differentiation, as opposed to tumor growth. In SH-SY5Y cells, ATRA treatment is able to inhibit cell growth potential, inducing clear morphological changes, such as the protrusion of neuritic extensions.

To test whether the expression of miR-128, a neuronspecific microRNA, is somehow modulated during ATRA treatment of SH-SY5Y cells, we treated these cells with $10 \mu \mathrm{M}$ ATRA for $6 \mathrm{~d}$. We assessed this treatment and found that it reproducibly induced morphological differentiation of SH-SY5Y cells (Fig. 1A), as confirmed also by the up-regulation of Gap43 (Fig. 1B), a protein involved in neurite outgrowth (36), and we demonstrated that miR-128 expression was up-regulated $(\sim 3$ fold) in treated cells as compared to untreated ones (Fig. 1C).

\section{The protein expression of Reelin and DCX, two predicted targets of miR-128, is down-regulated in ATRA-treated SH-SY5Y cells}

To identify the functional significance of the observed miR-128 induction, we performed a bioinformatic screening (Targetscan: http://www.targetscan.org/, and PicTar: http:/ / pictar.bio.nyu.edu/) of miR-128 predicted target mRNAs, focusing on the two molecules specifically involved in the migration of neuronal cells: Reelin and DCX. The bioinformatic search for microRNAs predicted to target the mRNAs of both molecules yielded miR-128 as the most likely candidate, highly ranked in both cases, with two predicted sites both in Reelin and in DCX mRNA 3'UTRs. Moreover, when comparing the human Reelin and DCX 3'UTRs for interspecies homology, we found that the miR-128 target sites are highly conserved among 6 and 5 species, respectively (Fig. 2A).
A
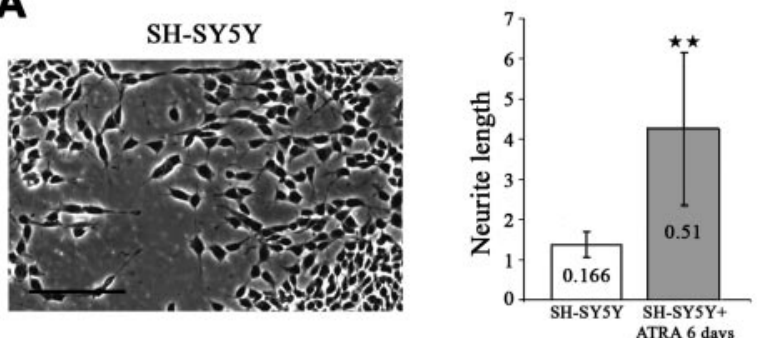

C

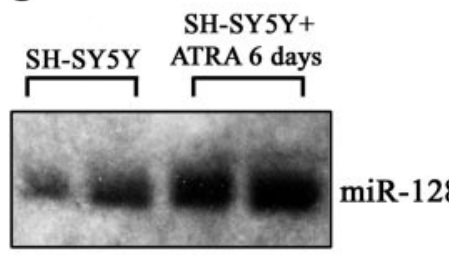

U6

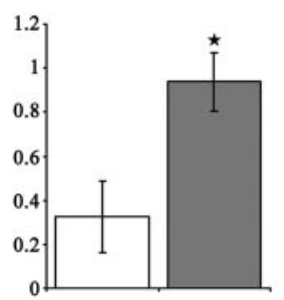

SH-SY5Y SH-SY5Y+ ATRA 6 days

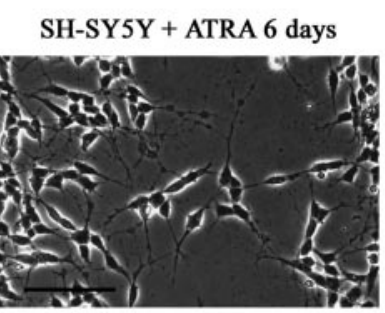

B

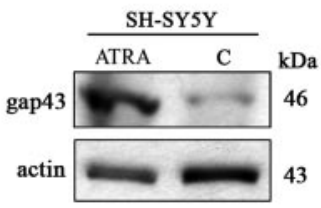

Figure 1. MiR-128 expression is up-regulated following neuronal differentiation of SH-SY5Y cells with ATRA. A) Representative images of SH-SY5Y cells differentiated by ATRA. Cells treated with $10 \mu \mathrm{M}$ ATRA display morphological changes, such as neuritic extensions, that are indicative of a differentiated state (right panel). Bar graph displays mean \pm sD neurite length in mock or ATRA-treated cells, calculated vs. 1 average diameter of control cells at $\mathrm{d} 0$. Average number of neurites per cell is also indicated for each treatment type. $B$ ) Western blot analysis of the expression of the neuronal marker Gap43 performed on total cell extracts from treated (ATRA) or control (C) SH-SY5Y cells. Actin immunoreactivity is shown as a loading control. C) Northern blot analysis of total RNA extracted from SH-SY5Y cells treated with $10 \mu \mathrm{M}$ ATRA for $6 \mathrm{~d}$. Hybridization to the U6 small nuclear RNA is shown as a loading control. Graph shows relative miR-128 expression. Error bars $=\mathrm{SD}$; $n=4$ samples. $* P<0.05$ vs. control. 


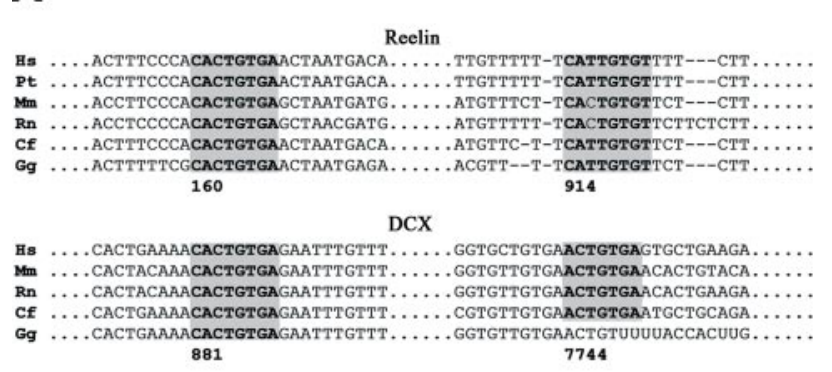

C
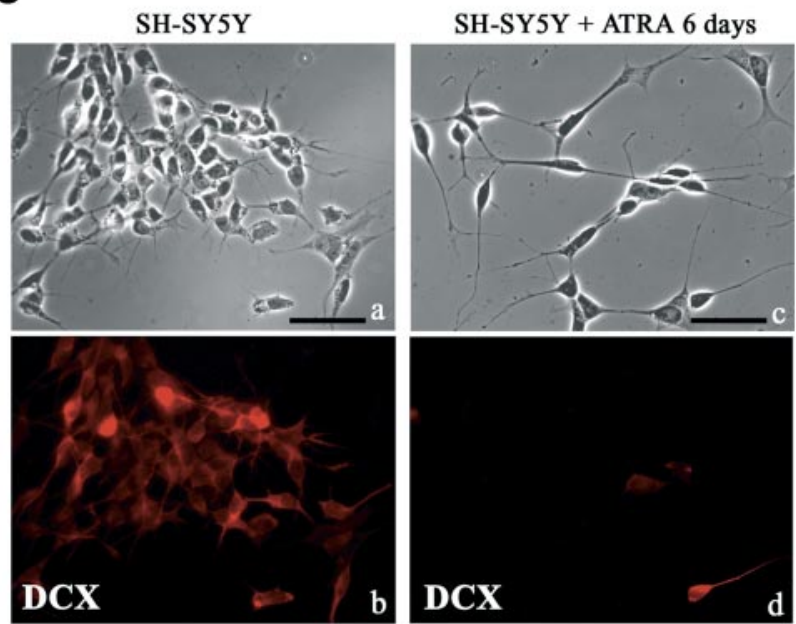

$\mathrm{Bar}=50 \mu \mathrm{m}$

B
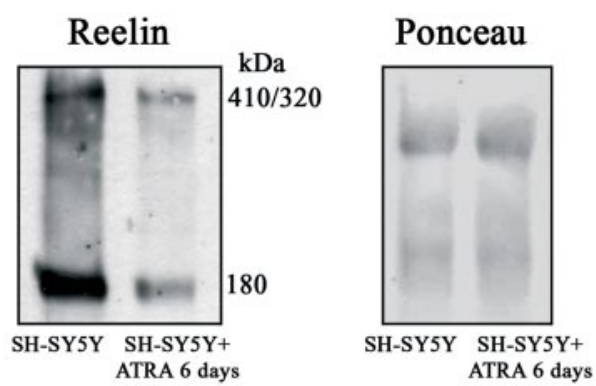

D
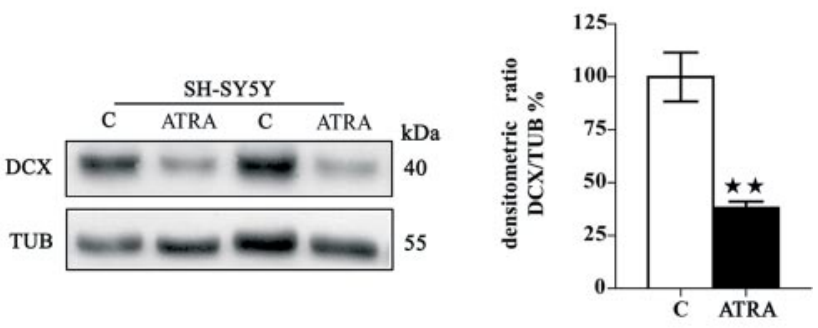

Figure 2. ATRA treatment lowers Reelin and DCX protein expression in SH-SY5Y neuroblastoma cells. A) 3'UTR alignments and location of predicted sites. Reelin and DCX 3'UTR sequences are numbered starting from the first 3 'UTR nucleotide. Hs, Homo sapiens; Pt, Pan troglodytes; Mm, Mus musculus; Rn, Rattus norvegicus; Cf, Canis familiaris; Gg, Gallus gallus. B) Effect of ATRA treatment on endogenous Reelin levels. Western blot analysis of secreted Reelin was performed on SH-SY5Y supernatants following 6 d of ATRA treatment. Left panel: differentiated SH-SY5Y cells show a marked reduction in Reelin levels. Right panel: Ponceau staining of the filter as a loading control. $C$ ) Effect of ATRA treatment on endogenous DCX levels. Phase contrast $(a, c)$ or immmunofluorescence images $(b, d)$ of SH-SY5Y cells before $(a, b)$ and after $(c, d)$ a 6 -d treatment with $10 \mu \mathrm{M}$ ATRA. After treatment, cells are morphologically differentiated, showing long neuritic processes $(c)$, and DCX immunoreactivity is severely reduced $(d)$, as compared to undifferentiated cells $(b)$. Scale bars $=50 \mu \mathrm{m} . D$ ) Effect of ATRA treatment on endogenous DCX levels. Western blot analysis of DCX expression performed on total cell extracts from treated (ATRA) or control (C) SH-SY5Y cells provides evidence of a strong reduction of DCX expression in differentiated cells. Bar graph shows densitometric quantification of the Western blot results. Relative DCX amounts are expressed as the ratio to tubulin expression, and represent the average \pm SE of 6 independent experiments. $* * P<0.01$.

To check whether an inverse correlation exists between miR-128 expression in neuroblastoma cells and that of miR-128 predicted targets, we analyzed the levels of Reelin and DCX after differentiation of SH-SY5Y cells. As shown in Fig. 2B, secreted Reelin protein levels significantly drop in differentiated cells as compared to control cells.

We recently demonstrated that RA treatment is able to down-regulate DCX expression in SK-N-SH neuroblastoma cells (23). SH-SY5Y is a cell line that was obtained by subcloning from SK-N-SH cells and is made of an almost homogeneous population of neuroblastic cells, widely showing $\mathrm{DCX}^{+}$immunoreactivity (Fig. 2Cb). As shown in Fig. $2 C d$, the presence of DCX-positive cells was drastically reduced after ATRA treatment. This result was confirmed by Western blot analysis performed on total cell lysates of ATRA-treated cells. Fig. $2 D$ shows that the extent of this reduction can be estimated at $61.9 \pm 11.9 \%$, as compared to untreated cells.

These results led us to hypothesize that the observed inverse relationship between miR-128 and Reelin and DCX protein expression could be due, at least in part, to a direct regulatory effect exerted by miR-128 on Reelin and DCX mRNAs.

\section{MiR-128 down-regulates Reelin and DCX protein levels in cultured neuroblastoma cells}

To have a closer view of the possible relationship inversely linking miR-128 to DCX and Reelin, we ectopically overexpressed miR-128 in SH-SY5Y cells and analyzed Reelin and DCX protein levels by Western blot analysis. Cells were transfected with DpA-miR-128, encoding for miR-128, or with control vector. Northern blot analysis of SH-SY5Y cells stably transfected with DpA-miR-128 showed high levels of the expected mature microRNA, whereas very little expression was detected in control-transfected cells (Fig. 3A). Western blot analysis showed that Reelin protein was clearly reduced in SH-SY5Y cells expressing high levels of miR-128, as compared with cells transfected with the empty vector (Fig. $3 B$ ). 


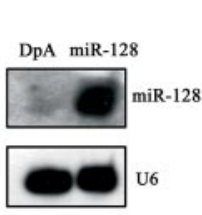

D

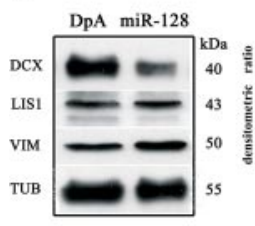

B
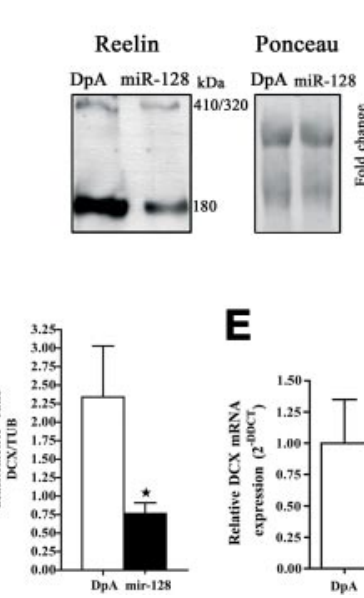

E

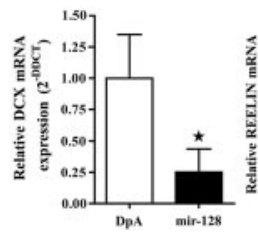

$\square \mathrm{DpA}$

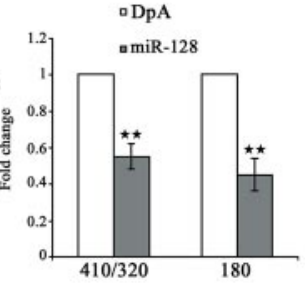

C
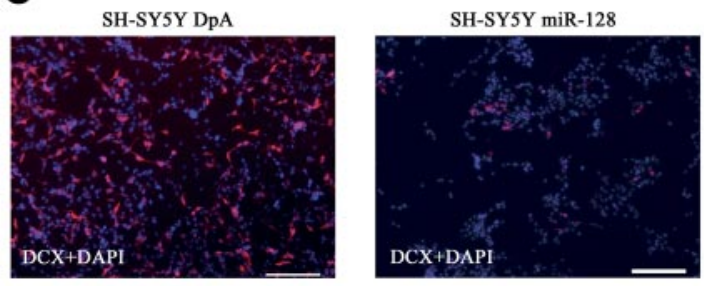

F

G

Figure 3. Ectopic expression of miR-128 down-regulates Reelin and DCX protein levels in SH-SY5Y cells, and its LNA-mediated depletion restores Reelin and DCX. A) Northern blot analysis of total RNA extracted from SH-SY5Y cells stably transfected with the empty vector (DpA) or DpA-miR-128 (miR-128). Hybridization to the U6 small nuclear RNA is shown as a loading control. $B)$ Left panel: Western blot analysis of Reelin. Supernatants from the same SH-SY5Y cells utilized in A. Right panel: Graph represents the quantification of the major Reelin bands in miR-128 transduced cells as compared to the empty vector (DpA) transfected cells. Error bars $=$ SD; 3 independent experiments. Center panel: Ponceau staining of the filter as a loading control. C) Immunofluorescence analysis of DCX expression in control (DpA) or miR-128-transfected SH-SY5Y cells. Red, DCX; blue, nuclei (DAPI staining). Scale bars $=300 \mu \mathrm{m}$. D) Left panel: Western blot analysis of DCX expression in DpA- or DpA-miR-128-transfected cells. Experiments also show that LIS1 and vimentin (VIM) are not affected by miR-128 ectopical expression. Right panel: Bar graph represents densitometric quantification of DCX vs. tubulin. Data are expressed as the average \pm SE of 6 independent experiments. E) Real-time RT-PCR analysis of DCX (left panel) or reelin (right panel) expression in DpA- or DpA-miR-128-transfected cells. Data are expressed as the average \pm SD of 2 independent experiments performed in triplicate. F) Northern blot analysis of miR-128 expression in SH-SY5Y cells transfected with an anti-miR-128 LNA antisense oligonucleotide and treated with $10 \mu \mathrm{M}$ ATRA for $6 \mathrm{~d}$. Lane 1: mock-transfected cells; lane 2: cells transfected with negative control LNA oligonucleotide (NC); lane 3: cells transfected with anti-128 antisense LNA oligonucleotide ( $\alpha 128$ ). Hybridization to the U6 small nuclear RNA is shown as a loading control. $G$ ) Western blot analysis of DCX and Reelin expression in SH-SY5Y cells transfected with an anti-miR-128 LNA antisense oligonucleotide, and treated with $10 \mu \mathrm{M}$ ATRA for 6 d. Lanes 1-3 correspond to total protein extracts from untreated cells (C); lanes 4-6 to protein extracts from ATRA-treated cells (ATRA). Lanes 1 and 4: mock-transfected cells; lanes 2 and 5: cells transfected with negative control LNA oligonucleotide; lanes 3 and 6: cells transfected with anti-128 antisense LNA oligonucleotide. Tubulin immunoreactivity is shown as a loading control. $* P<$ $0.05 ; * * P<0.001$.

DCX expression was also negatively affected in miR128-transfected SH-SY5Y cells. Fig. 3C shows the great reduction of $\mathrm{DCX}^{+}$cells in the SH-SY5Y cell line stably transfected with DpA-miR-128. This result is more clearly quantified by the Western blot analysis shown in Fig. 3D. The sharp decrease of DCX protein level was not accompanied by any perturbation of two other cytoskeletal proteins, LIS1 and vimentin, that, as we have already shown for other neuroblastoma cell lines, are modulated during ATRA-induced neuroblastoma cell differentiation (23).

Moreover, we also measured DCX mRNA levels by Q-RT-PCR in miR-128-transfected cells, and we verified that they were significantly reduced $(\sim 75 \%)$ as compared to those measured in control cells (Fig. $3 E$, left panel). On the contrary, reelin mRNA levels were not affected by miR-128 ectopic expression (Fig. 3E, right panel).

To measure the extent to which DCX and Reelin modulation is mediated by miR-128, we inhibited the endogenous miR-128 in SH-SY5Y cells by transfecting them with anti-miR-128-specific LNA antisense oligonucleotides, and evaluated DCX and Reelin protein amounts in RA-treated cells. The inhibition of miR-128 achieved in ATRA-treated cells was nearly 100\% (Fig. $3 F$ ) and corresponded to a significant enhancement of DCX and Reelin levels, returning very close to those observed in the absence of ATRA treatment. (Fig. 3G).

The results of miR-128-overexpression and loss-offunction experiments are complementary and suggest that miR-128 specifically down-regulates Reelin and DCX at the post-transcriptional level.

\section{The Reelin and DCX 3'UTRs are direct targets of miR-128}

To check the hypothesis that Reelin and DCX are targets of miR-128, we asked whether the 3'UTRs of their mRNAs are true functional targets of miR-128. We cloned DNA oligonucleotides containing both miR-128 target sequences identified in the $3^{\prime}$ UTR of Reelin into pRL-TK plasmid, downstream of the luciferase reporter gene. In parallel, we produced a second reporter construct in which the conserved miR-128 target sites were mutated in their seed regions. Transient cotransfection of HEK293 cells, lacking endogenous miR-128 expression, with the wild-type reporter construct to- 
gether with plasmid DpA-miR-128 led to a significant decrease of luciferase activity $(\sim 40 \%)$ as compared to the control (Fig. 4A). However, the activity of the reporter construct mutated at the specific miR-128 target sites was unaffected by the concomitant transfection of DpA-miR-128. Analogous results were obtained when we cloned the miR-128 predicted binding sites of DCX 3'UTR in the same pRL-TK-based construct: the presence of the wild-type sites was sufficient to significantly decrease luciferase activity $(57 \%)$, while the mutated sites were inactive (Fig. $4 B$ ). Thus, the two miR-128 target sites predicted in the Reelin and DCX $3^{\prime}$ UTRs are sufficient and necessary to induce the miR-128-mediated decrease of the corresponding protein products.

\section{MiR-128 decreases SH-SY5Y neuroblastoma cell growth and motility}

A key characteristic of tumor cells, highly related to their relative degree of aggressiveness, is their ability to
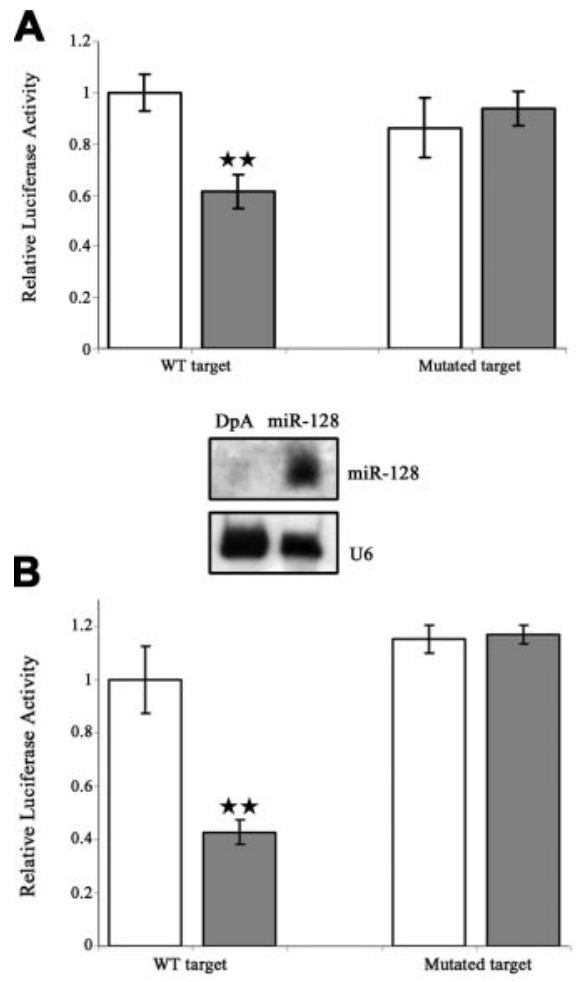

Figure 4. Reelin and DCX 3'UTRs are targets of miR-128. Luciferase reporter assays showing the regulatory action of miR-128 on Reelin $(A)$ and DCX $(B)$ 3'UTR sites. Reporter constructs containing wild-type or mutated DNA oligonucleotides representing target sequences for miR-128 from Reelin $(A)$ or DCX $(B)$ 3'UTRs were cotransfected into HEK293 cells with empty vector (DpA; white bars), or DpA-miR-128 (miR128; gray bars). Luciferase activity was determined $48 \mathrm{~h}$ after transfection. Values represent means \pm SD of 6 independent transfections. $* * P<0.001$. Center panel: Northern blot showing miR-128 expression in HEK293 cells transfected with empty vector (DpA) or DpA-miR-128 (miR-128). Hybridization to the U6 small nuclear RNA is shown as a loading control. migrate and eventually disseminate to distal sites. We aimed to check whether ectopic miR-128 expression is able to affect this aspect of neuroblastoma biology. To visualize the possible involvement of miR-128 expression in modulating SH-SY5Y cell motility, we used a wound-healing assay in cells stably transfected with DpA-miR-128 or with a control vector. The transfected cells were monitored for $24 \mathrm{~h}$, starting immediately after the initial wounding. As shown in Fig. 5C, $24 \mathrm{~h}$ after the scratch, control cells had almost fully recolonized the scratched area, while at the same time point, miR-128-expressing cells had only slightly moved into the area, and the distance between the borders of the wound was not significantly different from that measured immediately after scratching (Fig. $5 \mathrm{~B}$ ). Thus, the overexpression of miR-128 produced $46.3 \%$ reduction of cell migration rate with respect to SH-SY5Y cells transfected with the empty vector (Fig. $5 A$ ).

We also tested whether the overexpression of miR128 affects cell growth. Viability of DpA-miR-128 or control vector transiently transfected SH-SY5Y cells was determined by MTS assays. As clearly depicted in Fig. $5 D$, cells expressing ectopic miR-128 were significantly delayed in their growth, as compared to control cells $(\sim 30 \%$ at $48 \mathrm{~h}, \sim 22 \%$ at $96 \mathrm{~h})$.

\section{MiR-128 down-regulates neuroblastoma cell invasiveness}

To determine whether overexpression of miR-128 affects invasiveness of neuroblastoma cells, we carried out in vitro matrigel invasion assay, which is a reliable test to evaluate cancer cell invasiveness reflecting the ability of cancer cells to invade and metastasize in vivo. We used SH-SY5Y cells stably transfected with DpA-miR-128 or control vector. Cells were plated in a transwell Boyden chamber, and $48 \mathrm{~h}$ later, invasive cells on the bottom side of the membrane were dislodged and stained with a fluorescent dye. Fluorescence was counted using a multilabel reader. Data show that overexpression of miR-128 reduced the invasion of DpA-miR-128-transfected cells (Fig. $5 E$ ).

\section{Analysis of miR-128 expression in human primary neuroblastomas}

To test whether alterations of miR-128 expression might also be relevant in neuroblastic carcinogenesis in vivo, its expression was measured by Q-RT-PCR in a small set of untreated primary neuroblastoma tumors. The levels of miR-128 expression varied considerably in the different samples (Supplemental Fig. 1). Therefore, we considered whether different levels of miR-128 expression were associated with any particular clinicopathological features. We noticed a general trend for higher levels of expression to be associated with favorable features, such as early age at diagnosis, favorable Shimada 
A

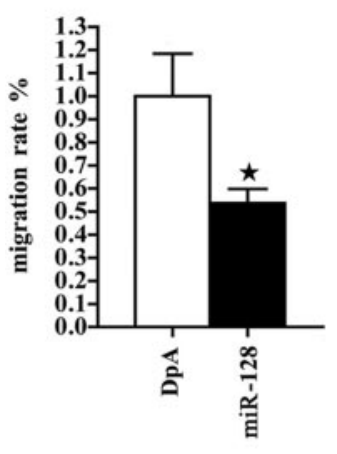

D

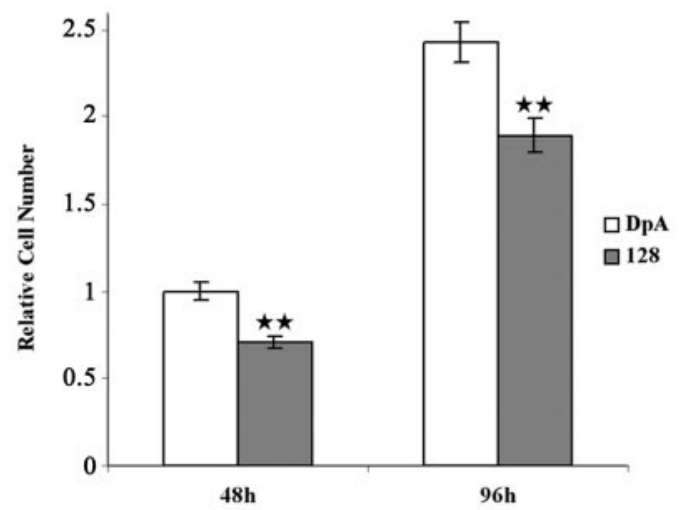

C

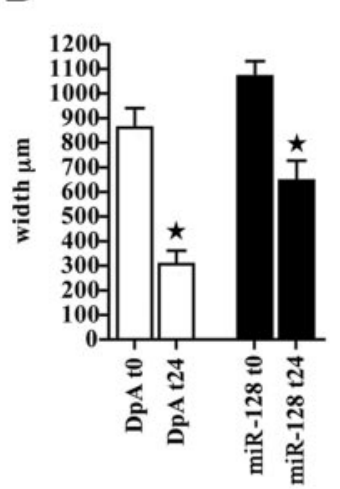

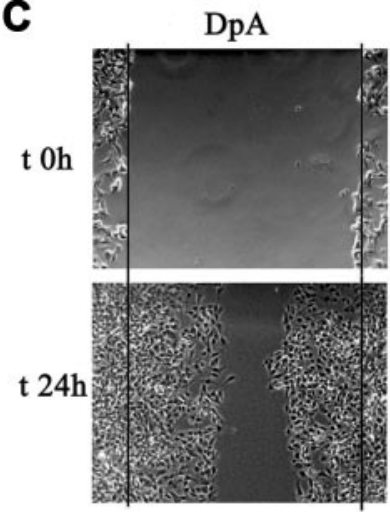

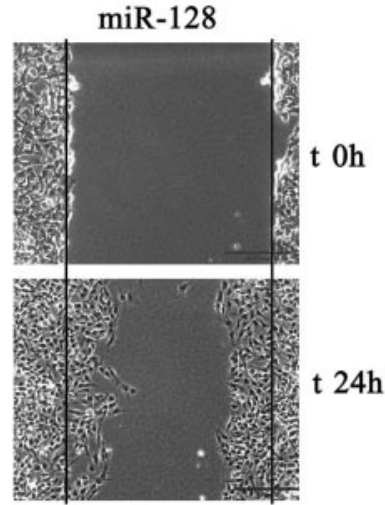

E

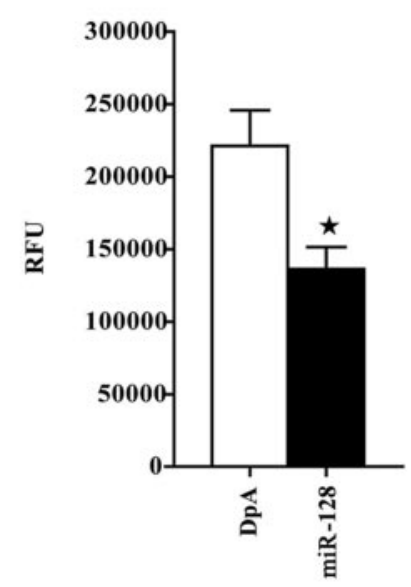

Figure 5. MiR-128 reduces the motility, growth, and invasiveness of SH-SY5Y neuroblastoma cells. $A-C$ ) Overexpression of miR-128 reduces cell migration rate with respect to the experimental control, consisting of empty-vector (DpA) transfection in a wound-healing assay on SH-SY5Y cells. Four different fields from each sample were considered for quantitative estimation of the distance between the borderlines; in each image, 4 different equidistant points were measured in order to better estimate the real width of the wounded area. A) Bars represent migration rate, expressed as a percentage of control and calculated

as the proportion of the mean distance between both borderlines caused by scratching to the distance that remained cell-free after regrowing. Data are expressed as the average \pm SE of 6 independent experiments. B) Bars represent scratch width measure. Data are averages \pm SE of 6 experiments. C) Representative images of the miR-128-induced reduction of SH-SY5Y cell migration in a wound-healing assay. Pictures were taken immediately after scratching the cultures $(t 0 \mathrm{~h})$ and $24 \mathrm{~h}$ later $(t 24 \mathrm{~h})$. This time interval was chosen because it is shorter than the SH-SY5Y cell doubling time. Scale bars $=$ $200 \mu \mathrm{m} . D)$ MiR-128 expression reduces cell growth. SH-SY5Y cells were transfected with either DpA control vector (DpA) or DpA-miR-128 (miR-128). Cell viability was determined at the indicated times after transfection by MTS assay. Values are averages \pm SD of 3 independent experiments. E) MiR-128 expression reduces cell invasiveness. Neuroblastoma cells transfected with either DpA control vector (DpA) or DpA-miR-128 (miR-128) were plated in matrigel invasion chambers and treated. After $48 \mathrm{~h}$ incubation at $37^{\circ} \mathrm{C}$, cells on the top surface of the chamber were gently removed. Invasive cells on the bottom of the membrane were detached and stained with a fluorescent dye. Fluorescence was counted using a multilabel reader. Data represent means \pm SE of 4 experiments. RFU, relative fluorescence units. $* P \leq 0.05$, $* * P<0.001$ vs. control.

category, prognostically favorable stages (stages $1,2,3$, and 4S), and MYCN single-copy status (Fig. 6). Although some associations individually reached statistical significance (not shown), these data need to be confirmed in a larger series of primary neuroblastomas. Nevertheless, they suggest that the miR-128 expression and functions that we characterized in neuroblastoma cell lines might also have an impact on the in vivo tumor behavior.
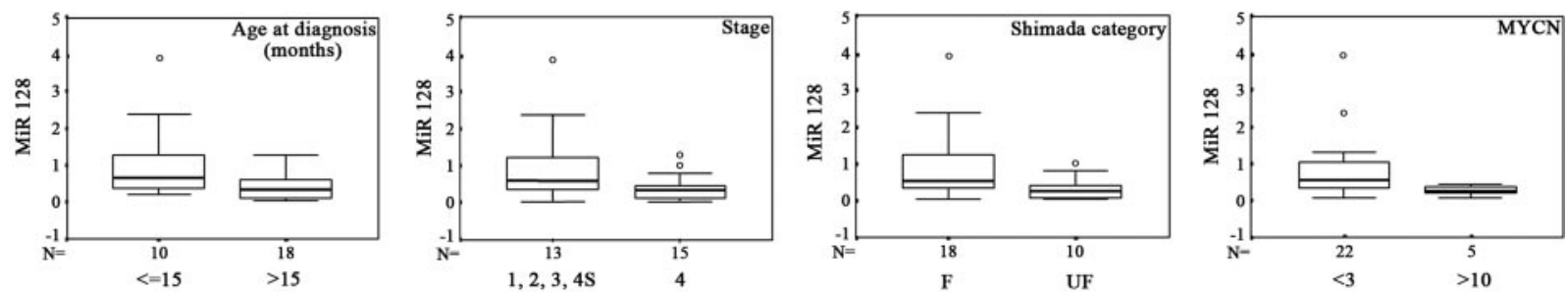

Figure 6. MiR-128 expression and clinical-pathological features in a series of 28 primary human neuroblastomas. Box-plot representation of miR-128 expression (as measured by Q-RT-PCR; see Supplemental Fig. 1) in NB primary samples stratified according to different clinical-pathological features. UF, unfavorable; F, favorable. One of the samples was undetermined for MYCN copy number and did not enter the analysis. 


\section{DISCUSSION}

In this report we describe for the first time the role of a neuronal enriched microRNA, miR-128, in the molecular changes taking place in neuroblastoma cells. A key result of our work is that we identified two targets of miR-128 action, Reelin and DCX, which are both involved in the migratory potential of neuronal cells, although via distinct mechanisms. It is noteworthy that the expression of miR-128 was significantly up-regulated following the induction of differentiation in SHSY5Y neuroblastoma cells. A specific activation of miR128 was previously described in analogous models of in vitro RA-induced differentiation of mouse P19 and human NTera-2/D1 cells (37) and was also detected by high throughput methods in SH-SY5Y cells, as well as in NT2 teratocarcinoma cells, treated with RA (38). Conversely, we have previously shown that miR-128 is the most down-regulated microRNA in GBM tumors and cell lines (10), and Mi et al. (39) showed that miR-128 is one of the most discriminatory microRNAs, clearly distinguishing acute lymphoblastic leukemia (ALL) from acute myeloid leukemia (AML). MiR-128 is strongly overexpressed in ALL, generally characterized by a better prognosis than AML. However, these observations have never gone beyond a mere description of miR-128 modulation, without further in-depth clarification of the biological meaning of miR-128 variant expression. Here, we have not only correlated miR-128 expression with the ability of neuroblastoma cells to proliferate and migrate through an extracellular matrix but have also identified two of the molecules through which miR-128 exerts its function. DCX has recently been described as a marker of SK-N-SH neuroblastoma cells that show high motility and invasiveness (23), and its expression in those cells has consistently been shown to be reduced by RA treatment. Our present data, besides confirming the down-modulation of DCX expression in response to RA in another neuroblastoma cell line, provide a first hint about the mechanism through which RA may work to reduce DCX and thus cell migration. To our knowledge, this is the first time that the modulation of Reelin protein expression is described in the context of neuroblastoma cell differentiation. In 2007, a study from Chen et al. (40) reported apparently conflicting results with regard to the positive regulation of the Reelin promoter after ATRA treatment. Nonetheless, the experimental conditions described in that report were significantly different from ours, mostly because in that case, the cells treated with ATRA were neuronal precursor cells, NT-2, which are very different from a tumor cell line such as SH-SY5Y. Also, Reelin protein level was not quantitated in that context (40).

In general, no studies have been performed that link Reelin and neuroblastoma, while it is already known that this protein is modulated in other cancer types $(25-27,41)$ in the majority of which, Reelin expression is directly correlated with tumor aggressiveness (2527). The present findings support the existence of another mechanism through which miR-128 reduces neuroblastoma cell motility and invasiveness, i.e., by reducing Reelin protein levels. This, in turn, confirms miR-128 as one of the mediators of RA action in neuroblastoma cells. A recent paper by Chen and Stallings (42) reported that 32 microRNAs are differentially expressed in distinct subtypes of primary neuroblastomas and compared the expression of these microRNAs in neuroblastoma SK-N-BE cells exposed to $5 \mu \mathrm{M}$ ATRA for $5 \mathrm{~d}$. In that in vitro system, the authors did not detect any variation of miR-128. However, this does not conflict with our findings, as Chen and Stallings did not study miR-128 but limited the analysis to the most significant microRNAs they detected in tumor samples and focused on MYCN-amplified (MNA) tumors vs. non-MNA tumors specifically studying the relationship between MYC, ATRA treatment, and microRNAs.

Our results, inversely linking miR-128 on one hand and Reelin and DCX on the other, are interesting as they provide further evidence of a "pleiotropic" way of action typical of microRNAs: one single microRNA yields a functional result (i.e., reduction of cell migration) by interfering with the production of multiple proteins, each of which is individually involved in the process that is being regulated. In fact, while DCX is a microtubule-associated protein that works as a modulator of neuroblastic migration via a totally intracellular pathway, Reelin is a secreted protein whose mechanism of action involves the binding to extracellular receptors. The multifaceted action of microRNAs is further confirmed in our work by the observation that miR-128 can reduce DCX mRNA levels, whereas it does not affect reelin mRNA amount. This is not an uncommon finding, as microRNAs are known to choose distinct ways of modulating distinct targets, even if the molecular basis of the different behaviors is still far from being explained. Some features can be recognized that actually distinguish reelin 3'UTR from DCX one. Both DCX and reelin mature mRNAs are very long molecules, but they are composed in two somehow complementary ways: a very long coding sequence followed by a relatively short $3^{\prime} \mathrm{UTR}$ for reelin $(\sim 10,400+1028 \mathrm{nt})$, and a short coding sequence followed by a huge $3^{\prime}$ UTR for DCX $(\sim 1300+7908 \mathrm{nt})$. The large extension of the latter 3 'UTR suggests a robust role for it in DCX mRNA stability. In any case, while the two miR-128 target sites in each mRNA are identical in their seed complementary sequences, they largely differ in the surrounding nucleotides. This likely contributes to the different effects of miR-128 onto reelin and DCX mRNAs.

MiR-128 pleiotropism can be relevant both for differentiation and tumor progression. Migration and, even more, invasion are a necessary requisite in neuronal maturation, but they are equally important in the acquisition of a critical tumor feature such as the ability to metastasize. While this manuscript was in preparation, Zhang et al. (43) demonstrated that miR-128 targets the transcription factor E2F3a in glioma cells, thus reducing their proliferation rate. On the basis of these findings, the study of the miR-128-E2F3a regulatory link 
deserves further study also in neuroblastoma. We have also shown that undifferentiated neuroblastoma cells do not express miR-128 but are able to activate expression when treated with RA. In addition, when miR-128 is forcedly expressed in untreated cells, it is sufficient by itself to produce some functional results typically induced by RA, such as the inhibition of proliferation, migration, and invasiveness. We can speculate that during the development of neuroblastoma, loss of miR-128 expression can occur in concomitance with an increase of aggressiveness and distant spread. Although our analysis of a small subset of primary neuroblastomas does not allow us to draw any definite conclusion, yet it provides some preliminary evidence for a reduced expression of miR-128 in stage 4 tumors as compared to locoregional neuroblastomas. More, in general, we found that higher miR-128 expression levels are associated with favorable clinicobiological features, such as very early age at diagnosis and favorable Shimada category. Whether confirmed in a larger series of primary neuroblastomas, these data would imply that the miR-128 activities we characterized in neuroblastoma cell lines might also impact on the in vivo tumor behavior. Consistent with this hypothesis is the observation that one of the two copies of miR-128, miR-128-2, is encoded by a gene located on chromosome 3p22.3, a region whose loss has been associated with the most aggressive forms of neuroblastoma $(44,45)$. To date, no tumor suppressor gene mapping to this region has been identified, leaving open the possibility that miR128-2 may be the relevant element lost at 3p22.3.

Because of the very limited amount of material, we were unable to address whether DCX and Reelin protein expression significantly varied in primary tumors with high miR-128 expression. As it could be expected because of the large number of variables affecting mRNA expression, a Q-RT-PCR analysis of our small subset of primary tumors showed only marginally a correlation between miR-128 and DCX mRNA levels (not shown). Nevertheless, DCX expression was suggested as a reliable marker for the detection of disease dissemination and minimal residual disease in neuroblastoma (22), suggesting that the possibility of an association between miR-128, DCX, and neuroblastoma in vivo aggressiveness needs to be thoroughly addressed. Presently, no data are available regarding Reelin expression and neuroblastoma aggressiveness. These subjects, together with the enticing hypothesis that loss or reduction of miR-128 can be considered a marker of high-risk neuroblastoma, deserves further investigations.

\section{GONCLUSIONS}

We have demonstrated a new role of miR-128 in neuroblastoma as a modulator of Reelin and DCX. This underpins future studies aimed at defining whether a role as true tumor suppressor can be conferred to miR-128 and whether its expression levels can be ex- ploited as a new tool for categorizing risk class in this disease.

The authors are grateful to Dr. Pierluigi Altavista (Section of Toxicology and Biomedical Sciences, ENEA Research Center Casaccia, Rome) for performing the statistical analysis. This study was funded in part by grants from the Italian Ministry of Instruction, University and Scientific Research, FIRB RBNE01H3K5 to S.A.C., FIRB RBNE01MBEC and ItalyUSA Collaborative Programme, Ministry of Health to MGF, and from Associazione Italiana per la Ricerca sul Cancro, Ministry of Health, the National Research Council, the Ministry of University and Research, Telethon grant GGP07118 to G.G.

\section{REFERENCES}

1. Kato, M., and Slack, F. J. (2008) microRNAs: small molecules with big roles-C. elegans to human cancer. Biol. Cell 100, 71-81

2. Filipowicz, W., Bhattacharyya, S. N., and Sonenberg, N. (2008) Mechanisms of post-transcriptional regulation by microRNAs: are the answers in sight? Nat. Rev. Genet. 9, 102-114

3. Eulalio, A., Huntzinger, E., and Izaurralde, E. (2008) Getting to the root of miRNA-mediated gene silencing. Cell 132, 9-14

4. Watanabe, Y., Tomita, M., and Kanai, A. (2007) Computational methods for MicroRNA target prediction. Methods Enzymol. 427, 65-86

5. Bartel, D. P. (2004) MicroRNAs: Genomics, biogenesis, mechanism, and function. Cell 116, 281-297

6. Doench, J. G., and Sharp, P. A. (2004) Specificity of microRNA target selection in translational repression. Genes Dev. 18, 504511

7. Gao, F. B. (2008) Posttranscriptional control of neuronal development by microRNA networks. Trends Neurosci. 31, 20-26

8. Lee, R. C., Feinbaum, R. L., and Ambros, V. (1993) The C. elegans heterochronic gene lin-4 encodes small RNAs with antisense complementarity to lin-14. Cell 75, 843-854

9. Reinhart, B. J., Slack, F. J., Basson, M., Pasquinelli, A. E., Bettinger, J. C., Rougvie, A. E., Horvitz, H. R., and Ruvkun, G. (2000) The 21-nucleotide let-7 RNA regulates developmental timing in Caenorhabditis elegans. Nature 403, 901-906

10. Ciafrè, S. A., Galardi, S., Mangiola, A., Ferracin, M., Liu, C.-G., Sabatino, G., Negrini, M., Maira, G., Croce, C. M., and Farace, M. G. (2005) Extensive modulation of a set of microRNAs in primary glioblastoma. Biochem. Biophys. Res. Commun. 334, 13511358

11. Maris, J. M., Hogarty, M. D., Bagatell, R., and Cohn, S. L. (2007) Neuroblastoma. Lancet 369, 2106-2120

12. Castel, V., Grau, E., Noguera, R., and Martinez, F. (2007) Molecular biology of neuroblastoma. Clin. Transl. Oncol. 9, 478-483

13. De Bernardi, B., Nicolas, B., Boni, L., Indolfi, P., Carli, M., Cordero di Montezemolo, L., Donfrancesco, A., Pession, A., Provenni, M., di Cataldo, A., Rizzo, A., Tonini, G. P., Dall'orso, S., Conte, M., Gambini, C., Garaventa, A., Sonetti, F., Zanazzo, A., D'Angelo, P., and Bruzzi, P. (2003) Disseminated neuroblastoma in children older than one year at diagnosis: comparable results with three consecutive high-dose protocols adopted by the Italian Co-Operative Group for Neuroblastoma. J. Clin. Oncol. 21, 1592-1601

14. Des Portes, V., Pinard, J. M., Billuart, P., Vinet, M. C., Koulakoff, A., Carrie, A., Gelot, A., Dupuis, E., Motte, J., Berwald-Netter, Y., Catala, M., Kahn, A., Beldjord, C., and Chelly, J. (1998) A novel CNS gene required for neuronal migration and involved in X-linked subcortical laminar heterotopia and lissencephaly syndrome. Cell 92, 51-61

15. Yang, H. K., Sundholm-Peters, N. L., Goings, G. E., Walker, A. S., Hyland, K., and Szele, F. G. (2004) Distribution of doublecortin expressing cells near the lateral ventricles in the adult mouse brain. J. Neurosci. Res. 76, 282-295

16. Nacher, J., Crespo, C., and McEwen, B. S. (2001) Doublecortin expression in the adult rat telencephalon. Eur. J. Neurosci. 14, $629-644$ 
17. Mizuguchi, M., Qin, J., Yamada, M., Ikeda, K., and Takashima, S. (1999) High expression of doublecortin and KIAA0369 protein in fetal brain suggests their specific role in neuronal migration. Am. J. Pathol. 155, 1713-1721

18. Brown, J. P., Couillard-Despres, S., Cooper-Kuhn, C. M., Winkler, J., Aigner, L., and Kuhn, H. G. (2003) Transient expression of doublecortin during adult neurogenesis. J. Comp. Neurol. 467, $1-10$

19. Daou, M. C., Smith, T. W., Litofsky, N. S., Hsieh, C. C., and Ross, A. H. (2005) Doublecortin is preferentially expressed in invasive human brain tumours. Acta Neuropathol. 10, 472-480

20. Bernreuther, C., Salein, N., Matschke, J., and Hagel, C. (2006) Expression of doublecortin in tumours of the central and peripheral nervous system and in human non-neuronal tissues. Acta Neuropathol. 111, 247-254

21. Masui, K., Mawatari, S., Suzuki, S. O., and Iwaki, T. (2008) Evaluation of sensitivity and specificity of doublecortin immunostaining for the detection of infiltrating glioma cells. Brain Tumor Pathol. 25, 1-7

22. Oltra, S., Martinez, F., Orellana, C., Grau, E., Fernandez, J. M., Canete, A., and Castel, V. (2005) The doublecortin gene, a new molecular marker to detect minimal residual disease in neuroblastoma. Diagn. Mol. Pathol. 14, 53-57

23. Messi, E., Florian, M. C., Caccia, C., Zanisi, M., and Maggi, R. (2008) Retinoic acid reduces human neuroblastoma cell migration and invasiveness: effects on DCX, LIS1, neurofilaments-68 and vimentin expression. BMC Cancer 8, 30

24. Tissir, F., and Goffinet, A. M. (2003) Reelin and brain development. Nat. Rev. Neurosci. 4, 496-505

25. Perrone, G., Vincenti, B., Zagami, M., Santini, D., Panteri, R., Flammia, G., Verzì, A., Lepanto, D., Morini, S., Russo, A., Bazan, V., Tomasino, R. M., Morello, V., Tonini, G., and Rabitti, C. (2007) Reelin expression in human prostate cancer: a marker of tumour aggressiveness based on correlation with grade. Mod. Pathol. 20, 344-351

26. Seigel, G. M., Hackam, A. S., Ganguly, A., Mandell, L. M., and Gonzalez-Fernandez, F. (2007) Human embryonic and neuronal stem cell markers in retinoblastoma. Mol. Vis. 13, 823-832

27. Wang, Q., Lu, J., Yang, C., Wang, X., Cheng, L., Hu, G., Sun, Y., Zhang, X., Wu, and M., Liu, Z. (2002) CASK and its target gene Reelin were co-upregulated in human esophageal carcinoma. Cancer Lett. 179, 71-77

28. Encinas, M., Iglesias, M., Llecha, N., and Com'ella, J. X. (1999) Extracellular-regulated kinases and phosphatidylinositol 3-kinase are involved in brain-derived neurotrophic factor-mediated survival and neuritogenesis of the neuroblastoma cell line SH-SY5Y. J. Neurochem. 73, 1409-1421

29. Pfaffl, M. W. (2001) A new mathematical model for relative quantification in real-time RT-PCR [Online]. Nucleic Acids Res. 29, e45

30. Livak, K. J., and Schmittgen, T. D. (2001) Analysis of relative gene expression data using real-time quantitative PCR and the 2(-Delta Delta C(T)) method. Methods 25, 402-408

31. Yarrow, J. C., Perlman, Z. E., Westwood, N. J., and Mitchison, T. J. (2004) A high-throughput cell migration assay using scratch wound healing, a comparison of image-based readout methods. BMC Bio/Technol. 4, 21-30

32. Voigt, A., and Zintl, F. (2003) Effects of retinoic acid on proliferation, apoptosis, cytotoxicity, migration, and invasion of neuroblastoma cells. Med. Pediatr. Oncol. 40, 205-213

33. Mehta, K., Fok, J., Miller, F. R., Koul, D., and Sahin, A. A. (2004) Prognostic significance of tissue transglutaminase in drug resistant and metastatic breast cancer. Clin. Cancer Res. 10, $8068-$ 8076
34. Shimada, H., Ambrosia, I. M., Dehner, L. P., Hata, J., Joshi, V. V., and Roald, B. (1999) Terminology and morphologic criteria of neuroblastic tumours: recommendations by the International Neuroblastoma Pathology Committee. Cancer 86, 349-363

35. Brodeur, G. M., Pritchard, J., Berthold, F., Carlsen, N. L., Castel, V., Castelberry, R. P., De Bernardi, B., Evans, A. E., Favrot, M., and Hedborg, F. (1993) Revisions of the international criteria to neuroblastoma diagnosis, staging, and response to treatment. J. Clin. Oncol. 11, 1466-1477

36. Baetge, E. E., Hammang, J. P., Gribkoff, V. K., and Meiri, K. F. (1992) The role of GAP-43 in the molecular regulation of axon outgrowth and electrical excitability. Perspect. Dev. Neurobiol. 1, 21-28

37. Sempere, L. F., Freemantle, S., Pitha-Rowe, I., Moss, E., Dmitrovsky, E., and Ambros, V. (2004) Expression profiling of mammalian microRNAs uncovers a subset of brain-expressed microRNAs with possible roles in murine and human neuronal differentiation. Genome Biol. 5, R13

38. Landgraf, P., Rusu, M., Sheridan, R., Sewer, A., Iovino, N., Aravin, A., Pfeffer, S., Rice, A., Kamphorst, A. O., Landthaler, M., Lin, C., Socci, N. D., Hermida, L., Fulci, V., Chiaretti, S., Foà, R., Schliwka, J., Fuchs, U., Novosel, A., Müller, R.-U., Schermer, B., Bissels, U., Inman, J., Phan, Q., Chien, M., Weir, D. B., Choksi, R., De Vita, G., Frezzetti, D., Trompeter, H.-I., Hornung, V., Teng, G., Hartmann, G., Palkovits, M., Di Lauro, R., Wernet, P., Macino, G., Rogler, C. E., Nagle, J. W., Ju, J., Papavasiliou, F. N., Benzing, T., Lichter, P., Tam, W., Brownstein, M. J., Bosio, A., Borkhardt, A., Russo, J. J., Sander, C., Zavolan, M., and Tuschl, T. (2007) A mammalian microRNA expression atlas based on small RNA library sequencing. Cell 129, 1401-1414

39. Mi, S., Lu, J., Sun, M., Li, Z., Zhang, H., Neilly, M. B., Wang, Y., Qian, Z., Jin, J., Zhang, Y., Bohlander, S. K., Le Beau, M. M., Larson, R. A., Golub, T. R., Rowley, J. D., and Chen, J. (2007) MicroRNA expression signatures accurately discriminate acute lymphoblastic leukemia from acute myeloid leukemia. Proc Natl. Acad. Sci. U. S. A. 104, 19971-19976

40. Chen, Y., Kundakovic, M., Agis-Balboa, R. C., Pinna, G., and Grayson, D. R. (2007) Induction of the reelin promoter by retinoic acid is mediated by Sp1. J. Neurochem. 103, 650-665

41. Sato, N., Fukushima, N., Chang, R., Matsubayashi, H., and Goggins, M. (2006) Differential and epigenetic gene expression profiling identifies frequent disruption of the RELN pathway in pancreatic cancers. Gastroenterology 130, 548-565

42. Chen, Y., and Stallings, R. L. (2007) Differential patterns of MicroRNA expression in neuroblastoma are correlated with prognosis, differentiation, and apoptosis. Cancer Res. 67, 976-983

43. Zhang, Y., Chao, T., Li, R., Liu, W., Chen, Y., Yan, X., Gong, Y., Yin, B., Liu, W., Qiang, B., Zhao, J., Yuan, J., and Peng, X. (2009) MicroRNA-128 inhibits glioma cells proliferation by targeting transcription factor E2F3a. J. Mol. Med. 87, 43-51

44. Hoebeeck, J., Michels, E., Menten, B., Van Roy, N., Eggert, A., Schramm, A., De Preter, K., Yigit, N., De Smet, E., De Paepe, A., Laureys, G., Vandesompele, J., and Speleman, F. (2007) High resolution tiling-path $\mathrm{BAC}$ array deletion mapping suggests commonly involved 3p21-p22 tumour suppressor genes in neuroblastoma and more frequent tumours. Int. J. Cancer 120, 533-538

45. Mosse, Y. P., Diskin, S. J., Wasserman, N., Rinaldi, K., Attiyeh, E. F., Cole, K., Jagannathan, J., Bhambhani, K., Winter, C., and Maris, J. M. (2007) Neuroblastomas have distinct genomic DNA profiles that predict clinical phenotype and regional gene expression. Genes Chromosomes Cancer 46, 936-949

Received for publication April 6, 2009. Accepted for publication August 6, 2009. 